\title{
Synthesis of the Tricyclic Core of Alkaloid Securinol B Using a Cascade of Vilsmeier-Haack and Mannich Cyclizations $^{\dagger}$
}

2008

Vol. 10, No. 20

4501-4504

\section{Robin Larouche-Gauthier and Guillaume Bélanger* \\ Département de Chimie, Université de Sherbrooke, 2500 boulevard Université, Sherbrooke, Québec J1K 2R1, Canada}

guillaume.belanger@usherbrooke.ca

Received July 25, 2008

\section{ABSTRACT}

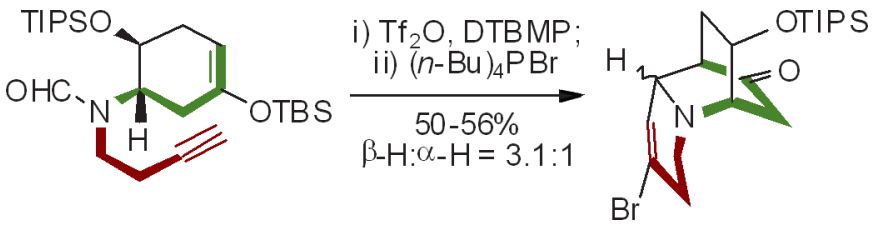

Iminium ions generated upon amide activation were trapped sequentially with tethered nucleophiles. This cascade of cyclizations constitutes a new synthetic strategy that was applied to the construction of the tricyclic core of alkaloid securinol $B$.

The Securinega alkaloids are a family of approximately 20 tetracyclic compounds isolated from diverse Securinega, Phyllanthus, and Margaritaria species of the Euphorbiaceae plant family. ${ }^{1}$ Most of these alkaloids possesses an indolizidine skeleton fused with an azabicyclo[3.2.1]octane system, as in securinine (1), the major Securinega alkaloid, and in viroallosecurinine (2) (Figure 1). These compounds exhibit interesting biological activity, such as acting on the central nervous system as $\gamma$-aminobutyric acid receptor antagonists. ${ }^{2}$ In 1965, Tamura and Iwamoto isolated much rarer hydroxysubstituted Securinega alkaloids, securinol A and B $(0.0005 \%$ and $0.00009 \%$, respectively), from $S$. suffriticosa. ${ }^{3}$ The structure of these alkaloids was first assigned as $\mathbf{3}$ and $\mathbf{4 .}^{3,4}$ In 1991, Arbain and Sargent identified 5 as the revised structure of securinol A, from X-ray analysis of its crystalline hydrobromide salt. ${ }^{5}$ Since both securinol $\mathrm{A}$ and $\mathrm{B}$ give viroallosecurinine (2) upon treatment with mesyl chloride

$\dagger$ Dedicated to Professor Larry E. Overman on the occasion of his 65 th birthday.

(1) Snieckus, V. The Alkaloids; Academic Press: New York, 1973; Vol. 14, pp 425-506.

(2) Beutler, J. A.; Karbon, E. W.; Brubaker, A. N.; Malik, R.; Curtis, D. R.K; Enna, S. J. Brain Res. 1985, 330, 135.

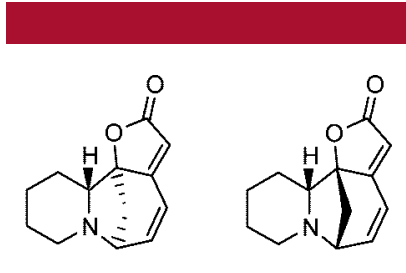

Securinine (1) Viroallosecurinine (2)

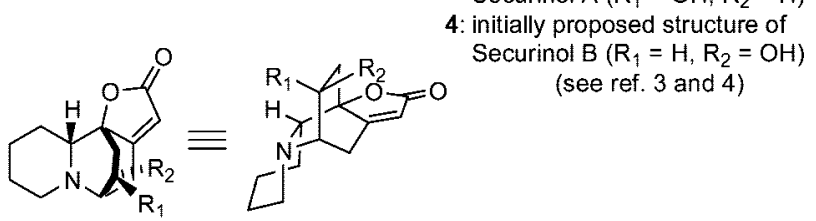

5: corrected structure of Securinol $A\left(R_{1}=O H, R_{2}=H\right)$

6: currently proposed structure of Securinol $B\left(R_{1}=H, R_{2}=O H\right)$ (see ref. 5)

Figure 1. Representative Securinega alkaloids.

and pyridine, ${ }^{4}$ it was therefore suggested that securinol B has structure $\mathbf{6}^{6}$

The uncommon quinolizidine skeleton fused to the azabicyclo[2.2.2] octane subunit of securinol $\mathrm{B}$ in addition 
Scheme 1. Retrosynthetic Analysis of Securinol B

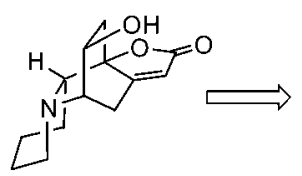

6
7

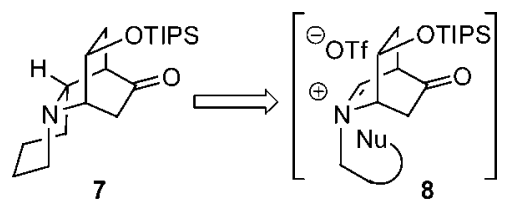

10

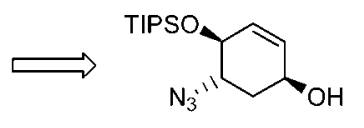

to the very limited supply of this alkaloid render it an attractive synthetic target. Furthermore, a synthesis of securinol B would lift the vail on the long standing ambiguity on the structure of this alkaloid. ${ }^{7}$

Recently, we reported the first Vilsmeier-Haack-type cyclizations of nonaromatic carbon nucleophiles onto iminium ions generated from activated amides. In all reported cases, a second iminium ion of lower oxidation state was generated and subsequently hydrolyzed or reduced. ${ }^{8}$ In this paper, we decided to trap this second iminium ion using a Mannich cyclization ${ }^{9}$ in a one-pot procedure. Molecular complexity would thus be rapildy built through this novel synthetic strategy, furnishing the tricyclic core of securinol $\mathrm{B}$ and related Securinega alkaloids in a single operation.

Our retrosynthetic analysis of securinol B (6) begins with removal of the butenolide ring to give 7 containing the key tricyclic core of the natural product (Scheme 1). Compound 7 was seen as the product of a cascade of two nucleophilic cyclizations onto the activated amide of 9: a first cyclization with the silyl enol ether would lead to the iminium intermediate $\mathbf{8}$, which would be trapped by a pendent nucleophile in a second cyclization to yield the azabicyclo[2.2.2] octane core 7 of securinol B. Finally, amide 9 would be obtained from the known allylic alcohol $\mathbf{1 0}^{10}$ after straightforward fonctionalization of the azide and of the allylic alcohol moieties.

The synthesis began with the opening of the known epoxide $11^{11}$ using sodium azide to furnish the azidohydrin 12 in good yield (Scheme 2). A route developed by

(3) Horri, Z.; Ikeda, M.; Tamura, Y.; Saito, S.; Kotera, K.; Iwamoto, T. Chem. Pharm. Bull. 1965, 13, 1307.

(4) Horri, Z.; Yamauchi, M.; Ikeda, M.; Momose, T. Chem. Pharm. Bull. 1970, 18, 2009.

(5) Arbain, D.; Birkbeck, A. A.; Byrne, L. T.; Sargent, M. V.; Skelton, B. W.; White, A. H. J. Chem. Soc., Perkin Trans. 1 1991, 1863.

(6) Recently, Ye et al. reported the isolation of a Securinega alkaloid, virosine $\mathrm{A}$, having a structure identical to the currently proposed structure of securinol B (6). See: Wang, G.-G.; Wang, Y.; Li, Q.; Liang, J.-P.; Zhang, X.-Q.; Yao, X.-S.; Ye, W.-C. Helv. Chim. Acta 2008, 91, 1124.

(7) To date, no synthesis of securinol A or securinol B is yet reported.

(8) (a) Bélanger, G.; Larouche-Gauthier, R.; Ménard, F.; Nantel, M.; Barabé, F. Org. Lett. 2005, 7, 4431. (b) Bélanger, G.; Larouche-Gauthier, R.; Ménard, F.; Nantel, M.; Barabé, F. J. Org. Chem. 2006, 71, 704.

(9) (a) Overman, L. E.; Ricca, D. J. In Comprehensive Organic Synthesis; Trost, B. M., Flemming, I., Heathcock, C. H., Eds.; Pergamon: Oxford, 1991; Vol. 2, p 1007. (b) Royer, J.; Bonin, M.; Micouin, L. Chem. Rev. 2004, 104, 2311.

(10) Wu, M. H.; Jacobsen, E. N. Tetrahedron Lett. 1997, 38, 7641.

Scheme 2. Synthesis of Silyl Enol Ether 14

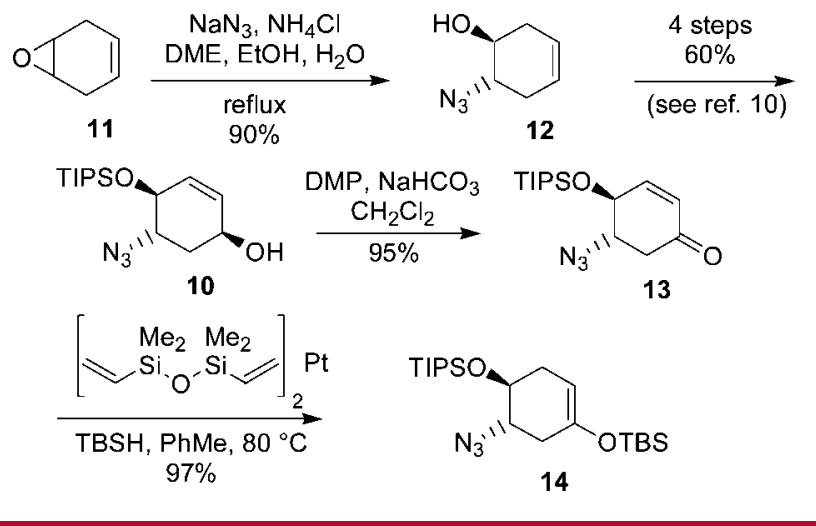

Jacobsen ${ }^{10}$ was then applied to access the racemic allylic alcohol 10, which was oxidized to the corresponding enone 13 using Dess-Martin periodinane.

Installation of the silyl enol ether was then accomplished by hydrosilylation of enone $\mathbf{1 3}$ with platinum divinyltetramethyldisiloxane (Karstedt's catalyst) ${ }^{12}$ and tert-butyldimethylsilane to afford $\mathbf{1 4}$ in a close to quantitative yield. The use of the more typical Wilkinson's catalyst $\left(\mathrm{Rh}\left(\mathrm{PPh}_{3}\right)_{3} \mathrm{Cl}\right)$ to promote this hydrosilylation $^{13}$ gave only marginal conversion, presumably due to the bulkiness of TBSH.

With the silyl enol ether regioselectively installed on the main cyclohexane ring, we wanted to test the feasibility of the preparation of the bridged bicyclic system $^{14}$ by a monocyclization on a formamide bearing a non-nucleophilic side chain to avoid competitive cyclization (Scheme 3 ).

Scheme 3. Synthesis and Monocyclization of Compound 15
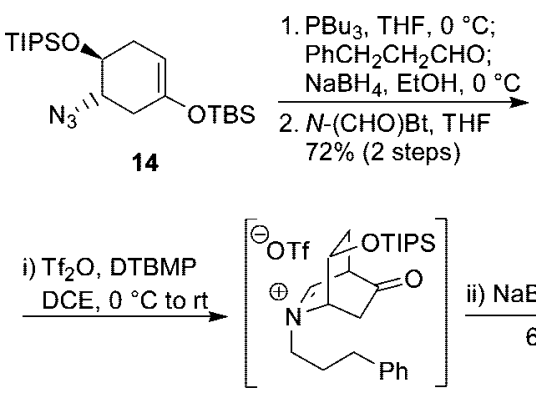

16

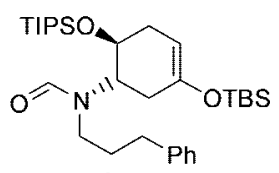

15
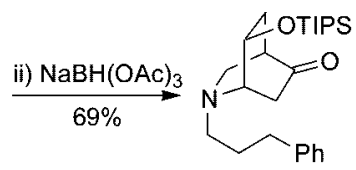

17
Azide 14 was first subjected to a Staudinger/aza-Wittig/ reduction sequence with hydrocinnamaldehyde. Among all phosphines tested $\left(\mathrm{PPh}_{3}, \mathrm{PMe}_{3}, \mathrm{PBu}_{3}\right), \mathrm{PBu}_{3}$ was far more

(11) Craig, T. W.; Harvey, G. R.; Berchtold, G. A. J. Org. Chem. 1967, $32,3743$.

(12) (a) Johnson, C. R.; Raheja, R. K. J. Org. Chem. 1994, 59, 2287.

(b) Miller, K. A.; Martin, S. F. Org. Lett. 2007, 9, 1113.

(13) Ojima, I.; Kogure, T. Organometallics 1982, 1, 1390.

(14) Altough we already studied monocyclization of silyl enol ether onto activated formamide (see ref 8 ), formation of a bridged systems using this reaction had never been tried. 
efficient in promoting the Staudinger reaction. We observed that rearrangment of the initial phosphazide to the iminophosphorane was quite slow: azide $\mathbf{1 4}$ had to react with $\mathrm{PBu}_{3}$ for $15 \mathrm{~h}$ prior to the addition of hydrocinnamaldehyde, otherwise the product resulting from addition of unrearranged phosphazide ${ }^{15}$ to hydrocinnamaldehyde was observed. Reduction of the resulting imine with $\mathrm{NaBH}_{4}$ followed by formylation with $N$-formylbenzotriazole ${ }^{16}(N-(\mathrm{CHO}) \mathrm{Bt})$ finally afforded formamide $\mathbf{1 5}$ in $72 \%$ yield over the two steps. When 15 was activated with $\mathrm{Tf}_{2} \mathrm{O}$ in the presence of 2,6di-tert-butyl-4-methylpyridine (DTBMP), the Vilsmeier-Haack cyclization occurred and the iminium ion $\mathbf{1 6}$ was cleanly formed. ${ }^{17}$ We had previously reported that cyclizations of acyclic silyl enol ethers onto activated amides are extremely fast (less than $15 \mathrm{~min}$ ). ${ }^{8}$ In the present case, the silyl enol ether is contained within a cyclohexane ring, resulting in a much slower reaction (several hours) due to the required high energy boat conformation of the cyclohexene ring for proper alignment of both the enol ether and the activated formamide. Even so, the cyclization occurred smoothly at room temperature. Iminium ion intermediate $\mathbf{1 6}$ was then reduced with $\mathrm{NaBH}(\mathrm{OAc})_{3}$ to give keto-amine 17.

We then investigated tandem cyclizations in order to access the tricyclic core of securinol B. We chose a vinylsilane side chain as an appropriate partner to trap the iminium ion intermediate obtained after the Vilsmeier-Haack cyclization, since a vinylsilane generates an endocyclic alkene in the cyclized product (cf. 24) that would only require a subsequent hydrogenation. ${ }^{18}$ To introduce the vinylsilane side chain, the aza-Wittig strategy we used in the preparation of the previous model compound $\mathbf{1 5}$ failed disappointingly in the present case, presumably because the acidity of the required $\beta, \gamma-$ unsaturated aldehyde resulted in the quenching of the iminophosphorane prepared from $\mathbf{1 4}$ (Scheme 4). We thus

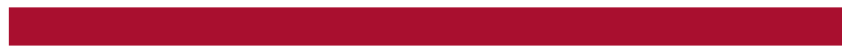

Scheme 4. Synthesis of Compounds 20 and 22

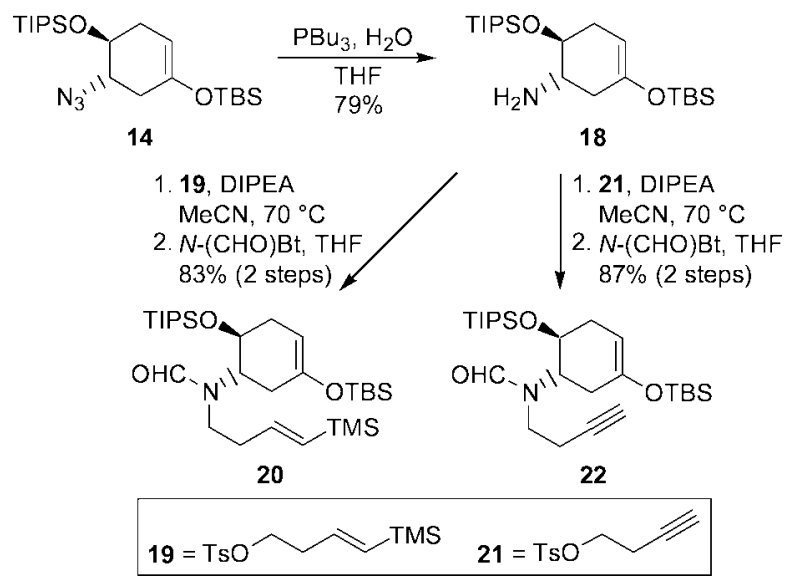

opted to reduce the azide to the corresponding amine $\mathbf{1 8}$ first. An attempted sequence of formylation followed by alkylation of the formamide anion with known homoallylic tosylate $\mathbf{1 9}^{19}$ also failed. ${ }^{20}$ The acidity of allylic protons in $\mathbf{1 9}^{21}$ led to elimination of the tosylate group, and only secondary formamide was observed in the crude reaction mixture.

Direct alkylation of amine 18 with 19 occurred at elevated temperature and afforded amide 20, after formylation, in good yield. Interestingly, only traces of the dialkylation product was observed, the second alkylation being prevented by the steric bulk of the OTIPS group adjacent to the primary amine. With the required amide $\mathbf{2 0}$ in hand, we then focused on the construction of the tricyclic ring system of securinol B.

Amide 20 was treated with $\mathrm{Tf}_{2} \mathrm{O}$, and with no surprise, the silyl enol ether cyclized onto the activated amide to give iminium ion 23 (Scheme 5). ${ }^{17}$ Unfortunately, it was not possible

Scheme 5. Tandem Cyclization Attempts with Compound 20

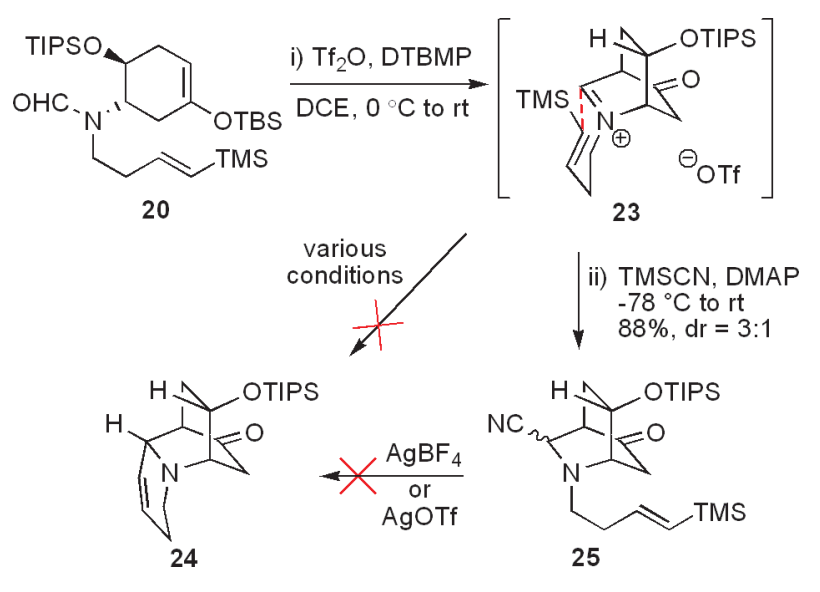

to promote the crucial Mannich cyclization (i.e., 23 to 24), and despite an extensive survey of reaction conditions, only decomposition was observed. Formation of the iminium ion intermediate was nonetheless proven by external nucleophilic trapping with a cyanide anion generated in situ from TMSCN and DMAP. ${ }^{22}$ Pure aminonitrile $\mathbf{2 5}$ was isolated in high yield. Treatment of the latter with silver salts and attempted subsequent Mannich cyclization were also unsuccessful.

We then turned our attention to a halide-promoted intramolecular alkyne addition to iminium ions previously developed by Overman ${ }^{23}$ as an alternative to the vinylsilane addition. The required homopropargylic amide $\mathbf{2 2}$ was readily obtained by

(15) Phosphazide can be sometimes isolated. See: Ylides and Imines of Phosphorus; Johnson, A. W., Eds.; Wiley: Chichester, 1993.

(16) Katritzky, A. R.; Chang, H. X.; Yang, B. Synthesis 1995, 503.

(17) As observed by ${ }^{1} \mathrm{H}$ NMR analysis of samples taken from the reaction mixture. See Supporting Information.

(18) For a review on vinylsilane-iminium ion cyclizations, see: Blumenkopf, T. A.; Overman, L. E. Chem. Rev. 1986, 86, 857.

(19) Made by tosylation of (E)-4-trimethylsilylbut-3-enol. See: Ménez, P. L.; Brion, J. D.; Lensen, N.; Chelain, E.; Pancrazi, A.; Ardisson, J. Synthesis 2003, 2530.

(20) Amide alkylation with homoallylic electrophiles are quite rare. For examples see: (a) Cappe, C. O.; Cochran, J. E.; Padwa, A. Tetrahedron Lett. 1995, 36, 9285. (b) Padwa, A.; Dimitroff, M.; Waterson, A. G.; Wu, T. J. Org. Chem. 1998, 63, 3986. (c) Duboc, R.; Hénaut, C.; Savignac, M.; Genet, J.-P.; Bhatnagar, M. Tetrahedron Lett. 2001, 42, 2461.

(21) The same is true for the corresponding iodide as well.

(22) (a) Armode, S. M.; Judd, A. S.; Martin, S. F. Org. Lett. 2005, 7, 2031. (b) Magnus, P.; Grizzard, L.; Hobson, L.; Payne, A. H.; Rainey, T. J.; Westlund, N.; Lynch, V. Tetrahedron 2002, 58, 3423. 
Scheme 6. Successful Tandem Cyclization with Compound 22

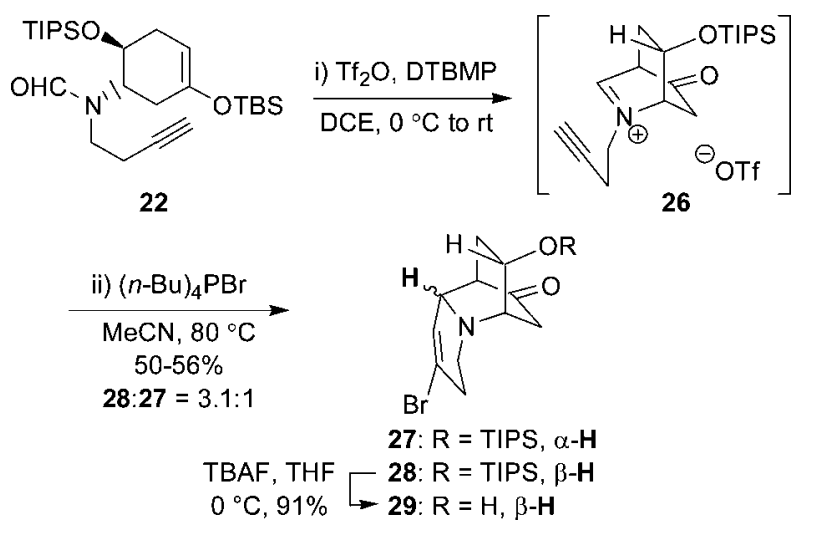

alkylation of amine $\mathbf{1 8}$ with known tosylate $2 \mathbf{1}^{24}$ followed by formylation (see Scheme 4). After extensive optimization, we found that iminium ion $\mathbf{2 6},{ }^{17}$ obtained upon activation of amide 22 with $\mathrm{Tf}_{2} \mathrm{O}$, could be converted to the key tricyclic compound 28 with the aid of tetrabutylphosphonium bromide. The overall yield and diastereomeric ratio were good, considering the rapid increase of molecular complexity in this single operation (Scheme 6).

To the best of our knowledge, this constitutes the first example of a double addition of carbon nucleophiles to the same iminium carbon generated from amide activation. ${ }^{25}$ Epimers $\mathbf{2 7}$ and $\mathbf{2 8}$ were easily separated by flash chromatography. The major diastereomer $\mathbf{2 8}$ was deprotected with TBAF to afford alcohol 29. The stereochemistry of the latter was unequivocally

(23) (a) Overman, L. E.; Sharp, M. J. J. Am. Chem. Soc. 1988, 110, 612. (b) Overman, L. E.; Rodriguez-Campos, I. M. Synlett 1992, 995. (c) Overman, L. E.; Sarkar, A. K. Tetrahedron Lett. 1992, 33, 4103. (d) Murata, Y.; Overman, L. E. Heterocycles 1996, 42, 549. (e) Lin, N. H.; Overman, L. E.; Rabinowitz, M. H.; Robinson, L. A.; Sharp, M. J.; Zablocki, J. J. Am. Chem. Soc. 1996, 118, 9062. (f) Caderas, C.; Lett, R.; Overman, L. E.; Rabinowitz, M. H.; Robinson, L. A.; Sharp, M. J.; Zablocki, J. J. Am. Chem. Soc. 1996, 118, 9073.

(24) Deng, B.-L.; Hartman, T. L.; Buckheit, R. W., Jr.; Pannecouque, C.; De Clercq, E.; Fanwick, P. E.; Cushman, M. J. Med. Chem. 2005, 48 , 6140.

(25) A single example of sequential cyclizations of carbon nucleophiles onto the same iminium carbon generated from carbamate activation was reported. See ref $22 b$.

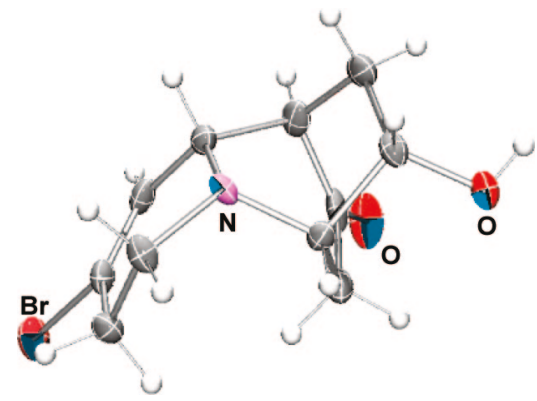

Figure 2. ORTEP representation of X-ray crystal structure of 29.

established by X-ray crystallographic analysis (Figure 2), proving that the alkyne addition to the iminium ion proceeded on the less hindered $\alpha$ face of iminium $\mathbf{2 6},{ }^{26}$ leading predominantly to the desired diastereomer $\mathbf{2 8}$.

In summary, a cascade of Vilsmeier-Haack/Mannich cyclizations was successfully developed and applied to the synthesis of the tricyclic core of alkaloid Securinol B. The synthetic strategy proved to be efficient in generating a bridged polycyclic structure in only one operation and opens access to other Securinega polycyclic alkaloids. Future efforts will be aimed not only at the completion of the synthesis but also at the application of this new tandem cyclization strategy to the synthesis of other alkaloids of different architecture.

Acknowledgment. This research was supported by the Natural Science and Engineering Research Council (NSERC) of Canada, FQRNT (Québec), the Canadian Fund for Innovation (CFI), and the Université de Sherbrooke. A NSERC doctoral fellowship to R.L.-G. is also gratefully acknowledged.

Supporting Information Available: . Experimental details and spectra for all new compounds. This material is available free of charge via the Internet at http://pubs.acs.org.

\section{OL801705S}

(26) The $\alpha$ face bears a $\mathrm{sp}^{2}$ carbon $(\mathrm{C}=\mathrm{O}) \beta$ to the iminium carbon, whereas the $\beta$ face bears a sp ${ }^{3}$ carbon $\left(\mathrm{CH}_{2}\right) \beta$ to the iminium carbon, with one of the hydrogens pointing over the iminium carbon. 